In the pilot study 41 children were Mantoux tested with $M$. scrofulaceum P.P.D. (Table I); only seven were positive, and in all of them the reaction was smaller than that caused by $M$. avium or Battey P.P.D.

All except one of the 25 children initially grade 1 whose Mantoux reactions indicated possible infection with $M$. tuberculosis were seen at least 12 months after the Heaf test. Nothing abnormal was found on physical examination or in the chest $x$-ray picture. Similarly 19 of the 21 children initially Heaf grade 2 were seen; all were normal on physical and radiological examination. One of the 20 children initially grade 3 or 4 had hilar lymph-node enlargement with a Ghon focus and was given anti-tuberculous drugs, 3 showed evidence of a calcified primary complex, and the remaining 16 were clinically and radiologically normal both immediately after the Heaf test and on follow-up at least 12 months later.

\section{Discussion}

The purpose of the routine Heaf testing of children aged 12-14 years in the United Kingdom is to separate them into two groups, those requiring B.C.G. vaccination and those requiring investigation of possible $M$. tuberculosis infection. Hitherto, Heaf-negative children have been vaccinated and Heaf-positive children have been examined clinically and radiologically.

This study of Heaf-positive children in Newham shows that the Heaf test as at present interpreted is too sensitive for this purpose-only $25\left(12^{\circ}\right)$ of 213 children who were initially grade 1 positive were likely to have been infected with $M$. tuberculosis; the other grade 1 positive reactions were not significant. None of these 25 children, 24 of whom were followed up for at least 12 months, had evidence of active tuberculosis, and our previous experience has been that neither the children with Heaf grade 1 reactions nor their families have active tuberculosis.

Our findings indicate that the investigation of all the Heaf grade 1 children would subject $88^{\circ}{ }^{\circ}$ of them to unnecessary chest $x$-ray examination and deny them the protection afforded by B.C.G. vaccine.

We recommend the routine B.C.G. vaccination of children with Heaf grade 1 reactions because we think that the risk of missing active tuberculosis in a small proportion of these children or their families is remote and far outweighed by the advantages to nearly $90 \%$ of the children of B.C.G. vaccination and the avoidance of unnecessary chest $x$-ray examination. We have already shown that the vaccination of children who are Heaf positive grade 1 does not give rise to any untoward reactions (Report, 1969).

We suggest, therefore, that Heaf grades 0 and 1 should be regarded as not significant and agree with Collins (1968) that the terms Heaf-negative and Heaf-positive should be abandoned in favour of "not significant" and "significant."

A more accurate division of the children into those likely to have been previously infected with $M$. tuberculosis and those who have not been infected could be made by double Mantoux testing using mammalian P.P.D. and atypical P.P.D. (Palmer and Edwards, 1968). Our results suggest that $M$. avium P.P.D. would be the most suitable in this country. Such a double Mantoux test would not be practicable in Newham, however, where the Heaf test is used because of its acceptability to schoolchildren and the ease and rapidity of performance. It is for this reason that we recommend the continued use of the Heaf test in 12-14-year-old children provided that the children with Heaf grades 0 and 1 are vaccinated and only those with grades 2,3 , and 4 are investigated for infection with $M$. tuberculosis.

This investigation was supported by a grant from the Research Group Council of the Society of Medical Officers of Health. We are grateful for the help of the following nurses in this investigation: Mrs. M. Baker, Mrs. I. Boyd, Mrs. M. G. Dillingham, Mrs. C. E. Moore, Mrs. M. O'Sullivan, Mrs. S. T. Roberts, Mrs. I. L. Ryan, and Mrs. E. R. Wozniak. We wish to thank Mr. R. Openshaw, Chief Education Officer, and the head teachers of Newham Secondary Schools for their co-operation.

\section{References}

Collins, T. F. B. (1968). South African Medical fournal, 42, 1285 Palmer, C. E., and Edwards, L. B. (1967). Archives of Environmental Health, 15,792 .

Palmer, C. E., and Edwards, L. B. (1968). Journal of the American Medical Association, 205, 167 .

Report (1969). Lancet, 2, 537.

\title{
Assessment of the Need for Continued Oral Therapy in Diabetics
}

\author{
A. M. TOMKINS, ARNOLD BLOOM
}

British Medical fournal, 1972, 1, 649-651

\section{Summary}

Hypoglycaemic agents were replaced by placebos in diabetic patients attending a hospital clinic. Of 62 patients observed, $43\left(69^{\circ}\right)$ relapsed within six months but blood sugar control remained unchanged in $19\left(31_{0}^{\circ}\right)$ during the period of observation.

\section{Introduction}

Tablet therapy for diabetes came into general use in 1956, and tolbutamide was one of the first drugs so to be used. Since then

Whittington Hospital, London N19 3UA

A M TOMKINS, M.B., B.S., M.R.C.P., Registrar ARNOLD BLOOM, M.D., F.R.C.P., Consultant Physician this type of treatment has been extended by the use of other compounds in the sulphonylurea group and by the introduction of the biguanides. From the beginning it had been realized that although oral therapy was successful in reducing blood sugar levels in mild diabetes, the long-term effects were less certain. In particular, it could not be predicted whether or not these compounds would be able to delay the appearance of the degenerative disorders that occur in long-standing diabete. In 1959 a group of American clinicians and statisticians met to discuss this problem and by 1961 a co-operative prospective study had been started in six university centres, later expanded to 12 , under the title of the University Group Diabetes Program $(1970,1971)$.

More than 800 recently diagnosed diabetic patients were assigned at random to various treatment groups. After a followup period ranging from five to eight years it emerged that the death rate from cardiovascular disease, both in the tolbutamidetreated group and in the phenformin-treated group, was sig- 
nificantly higher than in the placebo group. These unpalatable conclusions have not found support from similar studies in the same field (Keen and Jarrett, 1970; Passikivi, 1970), and the findings have been criticized for many reasons (British Medical Fournal, 1970; Constam, 1971; Lancet, 1971). In particular, many of the subjects in the American trial were borderline diabetics of the type usually treated in this country by simple dietary restriction without recourse to oral hypoglycaemic agents. Nevertheless the results were sufficiently disturbing to make necessary a further appraisal of this type of therapy and, in particular, to determine to what extent long-term continuous tablet treatment was necessary in maintaining diabetic control. With this in mind, tablets or capsules were replaced by placebos in a group of patients attending a diabetic clinic and the effects observed at regular intervals.

\section{Methods}

Patients attending the diabetic clinic were asked if they were willing to attend a special clinic at regular intervals to assess the effect of tablets different from those they were currently taking. Altogether 64 patients were studied. They were classified in four groups, each containing 16 patients, according to the type of therapy (Table I). Randomization was achieved by alphabetical selection, and no attempt was made to match the patients in the different groups with regard to age, sex, obesity, or duration of therapy. The mean age was 58.7 years (range 37 to 75 ) and $45.3 \%$ were men. All had been maintained on oral therapy because they had failed to respond to diet alone when first diagnosed. The mean duration of tablet treatment was 3.8 years (range 6 months to 11 years).

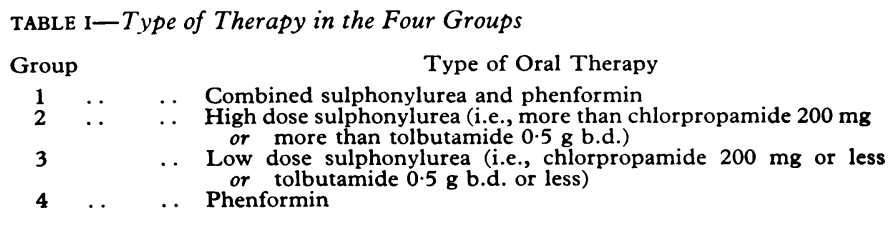

Patients were requested to maintain their usual diet and to attend each fortnight about two hours after lunch. At each visit blood glucose levels (AutoAnalyzer) and body weight were recorded. For the first three visits previous therapy was maintained. Placebo tablets were then substituted; these were identifiable as different from those previously taken but the total number taken daily was the same.

The degree of control before placebo substitution was assessed by the mean of the three blood glucose levels and classified according to the criteria of Muller et al. (1969) (Table II).

TABLE II-Degree of Control of Patients before Substitution: Mean of Three Blood Sugars taken Two Hours after Lunch. Specimens of Venous Blood, Glucose Estimated by the Glucose Oxidase Method using Guiacum

\begin{tabular}{ll|r|r|r|r}
\hline \multicolumn{1}{c}{ Control } & & \multicolumn{3}{|c|}{ Group } \\
\cline { 3 - 6 } & & 1 & 2 & 3 & 4 \\
\hline Excellent $(<130 \mathrm{mg} / 100 \mathrm{ml})$ &.. & 9 & 11 & 9 & 12 \\
Good $(130-150 \mathrm{mg} / 100 \mathrm{ml})$ &. & 4 & 1 & 3 & 4 \\
Fair $(150-180 \mathrm{mg} / 100 \mathrm{ml})$ &. & 3 & 4 & 4 & - \\
Poor $(>180 \mathrm{mg} / 100 \mathrm{ml})$ &.. & - & - & - & - \\
\hline & Total & 16 & 16 & 16 & 16 \\
\hline
\end{tabular}

Placebo tablets were maintained so long as the blood glucose levels remained within the same grade. Relapse due to deterioration into a lower grade led to the reintroduction of the previous oral therapy.

\section{Results}

Patients were observed until relapse occurred or for a minimum of six months. There were two defaulters from group 4 (phenformin).

Relapse Rate.-Fourteen (87\%) patients in group 1 had relapsed within two months (Table III). Relapse in the sulphonylurea groups 2 and 3 was unaffected by the dosage; $11(69 \%)$

\begin{tabular}{|c|c|c|c|c|c|}
\hline \multirow[t]{2}{*}{ Group } & \multirow[t]{2}{*}{$\begin{array}{l}\text { No. of } \\
\text { Cases }\end{array}$} & \multicolumn{2}{|c|}{ No. Relapsed at } & \multicolumn{2}{|c|}{$\begin{array}{c}\text { Mean Blood Glucose } \\
(\mathrm{mg} / 100 \mathrm{ml})\end{array}$} \\
\hline & & 3 Months & 6 Months & Before Trial & At Relapse \\
\hline $\begin{array}{l}1 \\
2 \\
3 \\
4\end{array}$ & $\begin{array}{l}16 \\
16 \\
16 \\
14\end{array}$ & $\begin{array}{r}14 \\
10 \\
10 \\
6\end{array}$ & $\begin{array}{r}14 \\
11 \\
11 \\
7\end{array}$ & $\begin{array}{l}132 \\
120 \\
122 \\
103\end{array}$ & $\begin{array}{l}257 \\
251 \\
212 \\
212\end{array}$ \\
\hline
\end{tabular}

in each group relapsed within six months. Half of the patients on phenformin (group 4) relapsed within six months. Of the 19 patients who had not relapsed at six months, 16 were followed to 10 months and one only (in group 1) relapsed. Relapse in all patients occurred rapidly and was accompanied by considerable rise in blood glucose (Table III). All patients who relapsed responded when the former therapy was reintroduced. There was no significant relation between the degree of control and tendency to relapse or between length of previous therapy and tendency to relapse.

The degree of obesity was assessed according to the Broca index. As expected there were more obese patients in the phenformin group, and it was in this group that the two defaulters occurred. They would not tolerate the increase in weight which occurred despite satisfactory blood glucose control. There was no significant relation between obesity and tendency to relapse.

\section{Discussion}

When oral therapy was first introduced anxiety was felt about the possible immediate dangers of this form of treatment. Hence, tablets were introduced only in mild diabetic patients who could not be restored to normoglycaemia on simple dietary restriction. In one trial the patients treated with tolbutamide in this way were maintained on therapy for six weeks and the tablets were then discontinued. Of 78 such patients, 53 remained well controlled for periods of observation from 4 to 18 months on the same diet that manifestly was inadequate in restoring normoglycaemia before tolbutamide was introduced (Crowley et al., 1957; Bloom, 1959). In the ensuing years it gradually became apparent that the oral hypoglycaemic agents were largely free from immediate toxic effects and hence tablets have been used more and more widely as long-term treatment. In 1960 at one clinic $42 \%$ of patients with diabetes were treated with insulin, $40 \%$ were controlled on diet alone, and $18 \%$ were taking oral hypoglycaemic agents; by 1968 only $26 \%$ were on insulin, $26 \%$ were on diet, and $48 \%$ were on tablets (Bloom, 1969). Nevertheless, the underlying question remained unanswered. To what extent did oral therapy prevent or delay the onset of the degenerative changes that occur in long-standing diabetes?

The results of the American University Group Diabetes Program suggested that long-term tolbutamide or phenformin may be associated with an increased mortality rate from coronary thrombosis. Although these results are not supported by the findings in this country of Keen and Jarrett (1970), it is clear that there is now an onus on clinicians not to use this form of therapy unless it can be shown that simple dietary restriction alone is unsuccessful in preventing hy perglycaemia. It is generally accepted that hyperglycaemia is in itself harmful in that it may give rise to troublesome symptoms and is associated with an increased morbidity (Keen et al., 1965).

It has been the practice in this country to introduce tablets only when simple dietary restriction has failed to restore normo- 
glycaemia, and the present trial refers to patients initially treated in this way. Yet, even in these patients, when oral therapy was discontinued $31^{\circ}$, remained as well controlled as when taking their tablets. These findings suggest that even when the need for tablet therapy has been established by a poor initial response to simple dietary restriction, the introduction of tablets should not be regarded as necessarily permanent. The dose can steadily be reduced and then discontinued if normoglycaemia is maintained. When hyperglycaemia recurs it seems reasonable, in the present state of our knowledge, to reintroduce tablet therapy at the previous effective dose level. There is no firm evidence that insulin is more or less effective than oral therapy in preventing the degenerative complications in diabetics who cannot be controlled on simple dietary restriction.

\section{References}

Bloom, A. (1959). British Medical Fournal, 2, 731

Bloom, A. (1969). Postgraduate Medical fournal, Phenformin Supplement.

Bloom, A. (1969). Postgraduate Medical
British Medical fournal, 1970, 2, 443.

British Medical fournal, 1970, 2, 443.
Constam, G. R. (1971). Diabetologia, 7, 237

Constam, G. R. (1971). Diabetologia, 7, 237 . 2, 327 .

Keen, H., et al. (1965). Lancet, 2, 505.

Keen, H., and Jarrett, R. H. (1970). In Atherosclerosis: Proceedings of the Second Symposium, ed. R. J. Jones, p. 435. New York, Springer.

Lancet, 1971, 1, 171 .

Muller, R., Bauer, G., Schroder, R., and Saito, S. (1969). Hormone and Metabolism Research, 178, Suppl. No. 1, p. 88.

Passikivi, J. (1970). Acta Medica Scandinavica, Supplement No. 507.

University Group Diabetes Program (1970). Diabetes, 19, Suppl. No. 2, p. 747.

University Group Diabetes Program (1971). fournal of the American Medical Association, 217, 777.

\title{
Toxicity of Trimethoprim-Sulphamethoxazole in Patients with Megaloblastic Haemopoiesis
}

\author{
I. CHANARIN, J. M. ENGLAND
}

British Medical fournal, 1972, 1, 651-653

\begin{abstract}
Summary
Four consecutive patients with megaloblastic anaemia who also received therapy with trimethoprim-sulphamethoxazole all showed poor responses to specific haematinic therapy. This was attributed to trimethoprim, which suppressed reticulocyte responses in three cases and produced a pancytopenia in two and a falling haemoglobin with neutropenia in a third. A fourth patient, with pernicious anaemia, had a satisfactory reticulocyte response but experienced no clinical benefit until after withdrawal of trimethoprim.
\end{abstract}

Trimethoprim seems not to be a safe form of therapy in patients with a megaloblastic process; many of the toxic reactions reported with this drug may be on the basis of an unrecognized megaloblastic form of haemopoiesis.

\section{Introduction}

The trimethoprim-sulphamethoxazole drug combination has been in clinical use since 1968 and relatively few serious haematological complications associated with its administration have been recorded.

Whitman (1969) found that $1 \mathrm{~g}$ of trimethoprim daily given to healthy volunteers produced megaloblastic marrow changes in 8 out of 10 subjects. A similar dose given to 13 patients with chronic urinary trace infection produced some evidence of haematological change in 11-that is, leucopenia, thrombocytopenia, or appearance of hypersegmented neutrophils (Kahn, Fein, and Brodsky, 1968).

In the first six months after the introduction of the drug combination Hanley (1969) collected four examples of depression of leucocytes, nine of thrombocytopenia or purpura, and one report of aplastic anaemia. Allison, Kennedy, Mc-

Northwick Park Hospital and Clinical Research Centre, Harrow, Middlesex

I. CHANARIN, M.D., M.R.C.PATH., Consultant Haematologist Council
J. MAND, M.B., B.S., B.SC., Research Fellow of the Medical Research
Geachie, and McDonald (1969) did not find any appreciable blood changes in 25 women treated for seven days, although there was a significant fall in serum folate level. Hughes (1969) did not record any blood changes in 25 chronic bronchitics treated for seven days.

One patient with thrombocytopenia and megaloblastic marrow changes among 10 chronic bronchitics given $250 \mathrm{mg}$ of trimethoprim and $500 \mathrm{mg}$ of sulphamethoxazole twice daily for three months was found by Jenkins, Hughes, and Hall (1970). A further case of megaloblastic anaemia with this drug combination was reported by Jewkes, Edwards, and Grant (1970). Anaemia, neutropenia, and thombocytopenia in a puerperal woman given trimethoprim-sulphamethoxazole was reported by Mohan (1969). Other examples of neutropenia were recorded by Paulley (1970), Evans and Tell (1969), McCarthy (1969), and Hulme and Reeves (1971). Three cases of thrombocytopenia were recorded by McPherson and Raik (1970) and Hammett (1970) and a fourth patient had pancytopenia with megaloblastic marrow.

Scragg and Rubidge (1971) treated African and Indian children with typhoid fever with trimethoprim and sulphamethoxazole for 21 days. Neutropenia was noted twice as often as in a chloramphenicol-treated control group. Two children with neutropenia were also noted to have a reticulocytosis after withdrawal of therapy. Dawson and Routledge (1971) reported the appearance of a megaloblastic marrow in a woman given trimethoprim-sulphamethoxazole in whom the red cell folate level was only $16 \mathrm{ng} / \mathrm{ml}$.

Urinary tract infection is a frequent complication in women with megaloblastic anaemia, and in the past we have used trimethoprim-sulphamethoxazole as the drug of choice. The purpose of this paper is to draw attention to the toxic effects of this drug when given to patients who also have a megaloblastic process and to describe the clinical and haematological changes in four consecutive patients so treated.

\section{Case Reports}

\section{CASE 1. NUTRITIONAL VITAMIN $B_{12}$ DEFICIENCY}

The patient, a 21-year-old Indian woman from Kenya, complained of a sore tongue for four weeks. She was a strict vegetarian. The haemoglobin concentration was $6.1 \mathrm{~g} / 100 \mathrm{ml}$, total white cell 